reaction from occurring? It should first be recognized that some women are at greater risk than others and that they include those who have had previous attacks of depression, those with progestogenic menstrual cycles, and those who normally suffer from premenstrual depression. Even despite the conclusions of Dr. Herzberg and her colleagues it may be wise to prescribe a weakly progestogenic or sequential oral contraceptive $^{5}$ and if more than one of these findings is present to advise some other method of contraception. Secondly, an assessment of mood should be part of the routine examination of all women taking oral contraceptives. Symptoms of depression should be looked for, as they may not be volunteered, and if necessary the doctor should advise changing or even abandoning the oral contraceptive.

\section{Reaching the Top}

The terms "stress" and "fitness" are imprecise and have bedevilled sports medicine for years. So said Dr. Roger Bannister at the recent Eighteenth World Congress of Sports Medicine held in Oxford. By "fitness" we generally mean the ability of an organism to maintain its internal equilibria as closely as possible to the resting state during strenuous exertion and to restore them promptly after exercise. "Stress", on the other hand, is the work programme imposed to increase a person's performance. The athlete under training has to follow with enthusiasm and exactitude a detailed and planned regimen if he is to improve his prowess effectively.

The chief physiological responses to athletic training are in general understood, ${ }^{1}$ but little is known about the precise and most efficient manner in which the changes that accompany repeated exercise are brought about. C. T. M. Davies and A. V. Knibbs ${ }^{2}$ have attempted to extend the work of R. J. Shephard ${ }^{3}$ in this respect by investigating the influence of prescribed courses of exercise varying in duration, intensity, and frequency of effort on "maximum aerobic power." This term is usually designated $\mathrm{VO}_{2}$ max, and is alternatively called by some authors "aerobic work capacity." It is the amount of oxygen a person consumes while working as hard as he can over a period of 15 to 30 minutes. It is usually expressed as so many $\mathrm{ml}$. of oxygen consumed per $\mathrm{kg}$. body weight per minute, and its magnitude is the most popular criterion of physical fitness. Many "normal" standards are available, and as aerobic power depends on the state of the heart the measurement of it has attracted interest as an indicator of health in relation to coronary artery disease. ${ }^{4}$

Experiments by Davies and Knibbs on healthy males showed that intensity and duration were the two most important factors in training a person to achieve his maximum aerobic power and that these were interdependent. No one who exercised below $50 \%$ of his $\mathrm{VO}_{2}$ max improved it. Even at the highest training intensities and the longest duration of effort improvements were small. It appears that to effect a change in the maximum aerobic power the athlete must be prepared to work hard for an appreciable time at or very near his $\mathrm{VO}_{2}$ max and that even then improvement may be disappointingly small.

1 Åstrand, P.-O., Physiological Reviews, 1956, 36, 307

2 Davies, C. T. M., and Knibbs, A. V., 18th World Congress of Sports Medicine, Oxford, 6-11 September, 1970. Abstracts, p. 39

3 Shephard, R. I, Canadian Medical Association fournal, 1967, 96, 899.

- Asmussen, E., Proceedings of the Royal Society of Medicine, 1969, 62, 1160
Investigations such as this show how difficult it is for the athlete after he has reached a high standard to improve his performance further. But in top-level athletics only a very small increase in attainment may make all the difference between success and failure.

\section{One Grim Spectre}

Acute dilatation of the stomach is rarely seen today, but early recognition of the condition is important, because untreated it may prove rapidly fatal. ${ }^{2}$

Once acute dilation becomes established enormous quantities of fluid accumulate within the stomach. Uncorrected, this rapid flux of body fluids leads to peripheral circulatory failure. Inhalation of vomit precipitating cardiac arrest is a common mode of death.

Early diagnosis demands a knowledge of the circumstances in which the condition may possibly develop. The early postoperative period is still the commonest, though the widespread use of prophylactic nasogastric suction after abdominal surgery has made this once feared complication a rarity. In 1933 a surgeon wrote ${ }^{3}$ : "Two grim spectres look over the shoulder of every operating surgeon; one is called pulmonary embolus and the other is called acute dilatation of the stomach."

Acute dilatation of the stomach occasionally occurs after the application of a plaster jacket or hip spica. The association is frequent enough to be described as the "body cast syndrome." " Usually it develops within a day or two of the plaster being applied, but occasionally it may appear after weeks or months in plaster. Recently four such patients have been described, ${ }^{5}$ one of whom died after aspiration of vomit. Acute dilatation has also been recorded after many other minor operations such as dilatation and curettage and interval appendicectomy. Rarely it complicates acute infections such as pneumonia or typhoid.

Sudden overloading of the stomach is occasionally the precipitating factor. Four emaciated prisoners of war who were suddenly given increased amounts of food developed acute dilatation. ${ }^{6}$ Chronic gastric dilatation was regarded as "the occupational disease of prisoners of war" who received a high-residue low-calorie diet; it seems likely that overdistension of the chronically dilated stomach precipitated complete atony. ${ }^{6}$

The pathology of acute gastric dilatation is not fully understood. There is no evidence of any mechanical obstruction, though the dilated viscus may virtually fill the abdominal cavity. Organic pyloric obstruction, both clinically and experimentally, produces a different effect. Reflex vagal inhibition causing gastric atony has been proposed to explain it, but it is curious that of all the viscera supplied by the vagus only the stomach is usually involved, and gastric secretion is not impaired-indeed sometimes it appears to be augmented. ${ }^{1}$ Another hypothesis ${ }^{1}$ is that it is a disorder of secretomotor (proximal) gut rather than absorption (distal) gut that results

\footnotetext{
1 Starr, K. W., Annals of the Royal College of Surgeons of England, 1953, 12,71 .

Leigh T. F fournal of the American Medical Association, 1960, 172, 1376 3 Henry, E. C., Nebraska State Medical fournal, 1933, 18, 209.

4 Dorp, M. H New England fournal of Medicine, 1950, 243, 440.

5or , M. New 303.

- Markowski, B., British Medical fournal, 1947, 2, 128.

Tarkowski, B., British Medical fournal, 1947, 2, 128 . their Surgical Treatment, p. 216. London, Balliere Tindall and Cox,
tho their Sur 1901 .
} 
from a disturbance of electrolyte circulation-that is, the balance of normal body reserves regulated by the processes of secretion and absorption-especially potassium and chloride. But it is difficult to see how such a mechanism would initiate dilatation soon after minor procedures such as the application of a plaster cast, though it may be responsible for maintaining the established case.

A similar acute clinical state has been observed in some patients who were found to have dilatation of the duodenum as far as the point where the superior mesenteric vessels cross the third part. This was recognized many years ago, and moving the patient into the prone position or on to the right side was shown to relieve symptoms in some patients. ${ }^{7}$ On the other hand, the gastric dilatation may have come first and the distension spread to the duodenum, so that compression by the superior mesenteric vessels is really a secondary and perhaps a not very significant phenomenon.

Clinically the onset of acute gastric dilatation may be insidious, with a period of apathy and listlessness before persistent vomiting begins. The vomiting is often bile-stained at first and later becomes brown or black. Physical examination discloses fullness in the left hypochondrium, often with hyperresonance. A plain radiograph of the abdomen shows the dilated viscus, and an erect film may show two fluid levels, one at the fundus and the second below it and to the right due to air trapped in the prepyloric region of the stomach. If any doubt exists the dilated viscus can be demonstrated easily by oral contrast medium.

Treatment is urgent, as circulatory collapse and aspiration of vomit may cause rapid deterioration and death. The stomach should be emptied with a wide-bore tube, and volumes of up to 8 litres have been removed from one patient. ${ }^{6}$ The electrolyte content of the aspirate should be measured as a guide to replacement therapy. Intravenous normal saline (together with potassium if appropriate) should be given to resuscitate the patient.

After the stomach is empty the large tube is replaced by a smaller nasogastric tube and the stomach aspirated until tone returns. Laying the patient prone or on the right side may assist the return of function. Any predisposing factor, such as a plaster cast, should be removed. Operation has little or no place in the management except for the occasional patient in whom a tube cannot be passed, when gastrostomy might be considered.

Most reported series still record a mortality ranging between 25 and $40 \%,{ }^{2} 5$ so that the importance of early diagnosis and energetic treatment cannot be overemphasized.

\section{Fetal Maturity}

Dissatisfaction with the results of assessing gestational age has led to a re-examination of traditional methods. ${ }^{1}$ As a result a bewildering array of new investigations has been introduced.

Clinical assessment of fetal weight is notoriously unreliable, ${ }^{2}$ and even measurement of the size of the uterus is subject to errors in early pregnancy. ${ }^{3} \mathrm{~T}$. Lind ${ }^{4}$ states that the single most valuable piece of information that a clinician can have is an accurate date of onset of the last menstrual period from a woman with a normal regular cycle, but the increasing use of oral contraceptive agents produces a common source of error.

Recently J. G. B. Russell has reported that radiological assessment of gestational age by Blair Hartley's methods is more accurate than menstrual data, ${ }^{5}$ and furthermore that bone maturation is related only to fetal age apart from some acceleration with anencephaly and maternal diabetes and delay with twins and spina bifida. ${ }^{6} \mathrm{~K}$. E. Scott and R. Usher, ${ }^{7}$ however, found that the absence of an upper tibial epiphysis does not distinguish between the underweight full-term baby and the gestationally premature infant. Studies on twins ${ }^{89}$ have conclusively shown the inherent errors in using biological criteria such as the ossification centres, which are subject to numerous influences both known and unknown for the assessment of fetal age.

Ultrasonic measurement of the biparietal diameter of the fetal skull between the twentieth and thirtieth weeks of pregnancy can predict the date of spontaneous delivery to within nine days in $95 \%$ of cases. ${ }^{10}$ Unfortunately, complex and expensive equipment as well as considerable experience is required for this. The method is unreliable after the thirtieth week, and furthermore one-third of babies classed as light for dates post partum had normal growth rates as assessed ultrasonically. ${ }^{11}$

Since the discovery that amniocentesis is a relatively safe procedure in experienced hands ${ }^{12} 13$ various characteristics of the amniotic fluid have been related to menstrual age. Amniocentesis is most difficult when the volume of liquor is low. ${ }^{14} \mathrm{I}$. Brosens and $\mathrm{H}$. Gordon ${ }^{15}$ related the proportion of anucleate squames staining orange with nile blue sulphate to sebaceous activity and hence to menstrual age. Fourteen out of 15 patients between 38 and 39 weeks had over $10 \%$ such cells and 11 patients at or beyond 40 weeks had over $50 \%$ of these cells. It was subsequently realized that absence of orange-staining cells does not exclude a post-term pregnancy. ${ }^{16} 17$ Staining amniotic fluid cells with haematoxylin and

1 Bentrem, G. C., Perkins, P., and Waxman, B., American fournal of Obstetrics and Gynecology, 1970, 106, 917.

Loeffler, F. E., Fournal of Obstetrics and Gynaecology of the British Commonwealth, 1967, 74, 675.

3 Smibert, J., Australian and New Zealand Fournal of Obstetrics and Gynae-

cology, 1962, 2, 125.
4 Lind, T., British fournal of Hospital Medicine, 1970, 3, 501.

5 Lind, T., British Fournal of Hospital Medicine, 1970, 3, 501. Commonwealth, 1969, 76, 208.

- Russell, J. G. B., and Rangecroft, R. G., Fournal of Obstetrics and Gynaecology of the British Commonwealth, 1969, 76, 497.

Scott, K. E., and Usher, R., New England fournal of Medicine, 1964, 270, 822 .

8 Dee, P. M., Parkin, J. M., and Simpson, W., Clinical Radiology, 1966, 17, 126.

Cope, I., and Murdoch, J. D., fournal of Obstetrics and Gynaecology of the British Empire, 1958, 65, 56.

10 Campbell, S., Fournal of Obstetrics and Gynaecology of the British Commonwealth, 1969, 76, 603 .

11 Willocks, J., Donald, I., Campbell, S., and Dunsmore, I. R., Fournal of Obstetrics and Gynaecology of the British Commonwealth, 1967, 74, 639. 12 Walker, W., British Medical fournal, 1970, 2, 220.

3 Freda, V. J., American Fournal of Obstetrics and Gynecology, 1965, 92, 341 .

14 Beischer, N. A., Brown, J. B., and Townsend, L., American fournal of Obstetrics and Gynecology, 1969, 103, 496.

Brosens, I., and Gordon, H., Fournal of Obstetrics and Gynaecology of the British Commonwealth, 1966, 73, 88.

6 Anderson, A. B. M., and Griffiths, A. D., Fournal of Obstetrics and Gynaecology of the British Commonwealth, 1968, 75, 300.

17 Chan, W. H., Willis, J., and Woods, J., Fournal of Obstetrics and Gynaecology of the British Commonwealth, 1969, 76, 193.

18 Lind, T., Parkin, F. M., and Cheyne, G. A., Fournal of Obstetrics and Gynaecology of the British Commonwealth, 1969, 76, 673.

19 Mandelbaum, B., and Evans, T. N., American fournal of Obstetrics and Gynecology, 1969, 104, 365.

20 Droegemueller, W., Jackson, C., Makowski, E. L., and Battaglia, F. C., American fournal of Obstetrics and Gynecology, 1969, 104, 424.

Huntingford, P. J., and Marsden, D., Geburtshilfe und Frauenheilkunde, 1966, 26, 867 .

22 Pitkin, R. M., International fournal of Gynaecology and Obstetrics, 1969, 7, 199.

23 Mandelbaum, B., La Croix, G. C., and Robinson, A. R., Obstetrics and Gynecology, 1967, 29, 471.

24 Pundel, J. P., Acta Cytologica, 1959, 3, 241.

25 Frampton, J., and Clayton, S. G., fournal of Obstetrics and Gynaecology of the British Commonwealth, 1968, 75, 42.

6 Henry, G. R., Fournal of Obstetrics and Gynaecology of the British Commonwealth, 1969, 76, 795.

27 Beischer, N. A., Brown, J. B., Smith, M. A., and Townsend, L., American fournal of Obstetrics and Gynecology, 1969, 103, 483. 